Revista Destaques Acadêmicos, Lajeado, v. 13, n. 2, 2021. ISSN 2176-3070

DOI: http://dx.doi.org/10.22410/issn.2176-3070.v13i2a2021.2599

http://www.univates.br/revistas

\title{
COMPORTAMENTO AGRESSIVO EM SUJEITOS PRIVADOS DE LIBERDADE: UMA REVISÃO INTEGRATIVA
}

\author{
Kaique Passos de Almeida ${ }^{1}$
}

\begin{abstract}
Resumo: Comum à espécie humana, o comportamento agressivo pode resultar em atitudes criminais, a depender de como é direcionado, sendo um construto estudado no contexto prisional. Esta pesquisa reúne conhecimentos de como o comportamento agressivo em sujeitos privados de liberdade é abordado na produção científica. Trata-se de uma revisão integrativa com síntese qualitativa. Pesquisou-se publicações brasileiras e internacionais, nas bases de dados LILACS, MEDLINE, IBECS e SciELO, com a utilização dos descritores "presos", "prisões", "crime", "criminosos" e "agressão". Após pré-seleção com base nos critérios de inclusão, obteve-se 34 artigos científicos dos quais 15 foram selecionados para a síntese. Objetivos, métodos e resultados dos estudos foram discutidos, bem como o referencial teórico abordado por estes. Concluiu-se que o comportamento agressivo em sujeitos privados de liberdade é frequentemente analisado em conjunto com variáveis como raiva, impulsividade e personalidade, atribuído à múltiplas motivações e, também, à dicotomia entre agressão reativa e proativa.
\end{abstract}

Palavras-chave: Agressão, Presos, Prisões.

\section{INTRODUÇÃO}

A privação de liberdade é um conceito existente em diversos contextos de diferentes sociedades, sendo seu significado volátil a depender da ótica pela qual se analisa, podendo ser até mesmo simplesmente metafórico. No contexto jurídico-penal, a pena privativa de liberdade não é um mero jogo de palavras: é uma condição imposta a sujeitos, significando, de fato, a detenção, reclusão.

No cenário brasileiro, a população privada de liberdade corresponde, aproximadamente, a 773.000 indivíduos, representando $60 \%$ da população presa na América do Sul e $7 \%$ dos presos no mundo todo, ficando atrás apenas de China (15\%) e Estados Unidos (19\%), e na frente dos números de Rússia, com aproximadamente 517 mil indivíduos presos e Índia, com aproximadamente 466 mil (ICPR, 2020). O ambiente onde a liberdade é cerceada abarca, em todos

1 Acadêmico de Psicologia da Universidade São Judas Tadeu, USJT, São Paulo, SP, Brasil. kaiqux@gmail.com. 
os continentes, diferentes modalidades: instituições para menores infratores, de acordo com a inimputabilidade etária que varia entre nações; internações em hospitais psiquiátricos e outras instituições de atenção à saúde mental, custódias estas que também seguem as peculiaridades de legislações pelo mundo; e as disseminadas unidades prisionais. No Brasil, estas últimas são compostas por penitenciárias, colônias agrícolas, industriais e similares, casa do albergado e cadeias públicas (INFOPEN, 2019).

Sujeitos privados de liberdade em unidades prisionais são objeto de investigações em múltiplos campos de estudo. Destaca-se a busca, nos últimos anos, por explicar a dinâmica destes indivíduos de forma heterogênea, considerando as possibilidades advindas do modelo biopsicossocial (BOURAS, 2017; FAVRIL et al., 2020; SHELTON et al., 2016). Dentre os aspectos estudados que envolvem este público-alvo, pode-se citar o uso de substâncias psicoativas, a incidência de transtornos mentais, a formação da personalidade e construtos como hostilidade, raiva, impulsividade e agressividade (COMAI et al., 2019; TAVARES; SCHAFFER; ALMEIDA, 2012). Este último torna-se uma interessante fonte de estudos na medida em que possibilita compreender as múltiplas manifestações do comportamento violento.

\section{Comportamento agressivo}

A agressão entre seres humanos é abordada em distintas disciplinas, que por sua vez, também possuem diferentes perspectivas teóricas na compreensão deste fenômeno, sendo os modelos integrativos, do campo da psicologia, aqueles que mais têm se destacado na formulação de sínteses que abrangem esta diversidade (KRISTENSEN et al., 2003).

O Modelo Geral da Agressão (BUSHMAN; ANDERSON, 2001) tem sido o mais proeminente dentre as linhas teóricas que abordam o comportamento agressivo. Caracteriza-se por compreender esse comportamento através de "estruturas de conhecimento", das quais se enfatizam os esquemas perceptuais, esquemas pessoais e scripts comportamentais, estruturas estas que conforme são utilizadas, podem se tornar automáticas e orientar a resposta dos sujeitos frente ao ambiente (KRISTENSEN et al., 2003). A agressão, neste modelo, é definida como qualquer comportamento que tem como primeira e imediata intenção causar dano a outrem, de tal modo que o autor deve acreditar no prejuízo que seu comportamento irá causar ao alvo, devendo este último estar motivado para evitar a agressão (BUSHMAN; ANDERSON, 2001).

Conforme Kristensen et al. (2003), o cognitivismo neoassociacionista (BERKOWITZ, 1998), o processamento da informação social (CRICK; DODGE, 1994) e o interacionismo social (TEDESCHI; FELSON, 1994) são linhas teóricas que também possuem importante contribuição no atual entendimento do comportamento agressivo, assim como as perspectivas clássicas da psicanálise, do behaviorismo e da aprendizagem social. 
Comum à espécie humana, o comportamento agressivo pode resultar em atitudes criminais, a depender de como é direcionado. Dados do Infopen (2019) mostram que os homicídios simples e qualificado somam pouco mais de $1 / 3$ dentre os crimes hediondos e equiparados. O comportamento agressivo pode também se manifestar em infrações de menor potencial ofensivo, como o porte de drogas para consumo próprio (BOTTI; MACHADO, 2015).

\section{Comportamento agressivo em sujeitos privados de liberdade}

Independentemente do delito cometido, qualquer sujeito privado de liberdade pode ser perpetrador de agressão, tanto em sua vida pregressa quanto no próprio contexto prisional. Cuomo et al. (2008) apontaram que comportamentos agressivos são mais presentes em detentos que fazem uso de substâncias psicoativas do que entre aqueles que não fazem, ainda que os delitos pelos quais os primeiros tenham sido condenados não tenham sido classificados como violentos.

O uso de substâncias é apenas uma das possíveis variáveis a serem analisadas em conjunto com a agressão, sendo outros fatores igualmente relevantes, como mostra o estudo baseado em um modelo multinível de Lahm (2007), que investigou agressões em uma amostra com 1054 detentos distribuídos em 30 prisões, constatando que a idade, a agressividade e a superlotação foram os principais preditores de ataques entre detentos, ou seja, presos altamente agressivos agiam mais violentamente em situações de superlotação e de maior quantidade de jovens, ressaltando ainda a importância de se considerar diferentes contextos no estudo do comportamento e da violência prisional. A psicopatia é outra variável comumente analisada em conjunto com a agressão; o estudo de Cima e Raine (2009), ao considerar a dicotomia entre agressão reativa e proativa/instrumental, sugeriu que a personalidade psicopata é predominantemente caracterizada pela agressão proativa, enquanto que alguns componentes da psicopatia são associados com a agressão reativa. Tratando-se de experiências traumáticas precoces, o trabalho de Cima, Smeets e Jelicic (2008) mostrou que estas estavam relacionadas com escores altos de comportamentos agressivos entre detentos não-psicopatas e participantes de um grupo controle, ao passo que não demonstravam associação entre detentos com características de psicopatia.

Além de pesquisas que tiveram como intento avaliar, investigar ou examinar, as intervenções que se propuseram a reduzir níveis de agressividade, raiva e violência entre detentos também fazem parte do objetivo de alguns estudos. Em uma revisão da literatura que levantou artigos de diferentes amostras, e não somente privados de liberdade, McGuire (2008) apresentou achados que se utilizaram de diferentes intervenções no manejo de comportamentos agressivos que se focavam em crenças agressivas, habilidades sociais e manejo da raiva. 
Ainda que diversos estudos tenham abordado o comportamento agressivo exclusivamente entre privados de liberdade, raras são as revisões que investigaram as diferentes propostas da produção científica relacionada a esta temática, de modo que não foi possível encontrar nenhum estudo semelhante em qualquer idioma. Investigações que sintetizem abordagens acerca do comportamento agressivo em sujeitos privados de liberdade são importantes na medida em que possibilitam o aprofundamento da literatura científica na compreensão da violência, fenômeno este ainda mais amplo e de difícil delimitação.

O presente estudo objetiva contribuir para o preenchimento desta lacuna, examinando as diferentes intervenções propostas visando o comportamento agressivo em sujeitos privados de liberdade, sendo estas as que consideram variáveis como idade, diferenças entre gêneros, nacionalidade, psicopatologias, uso de substâncias, entre outras, representadas em amostras obtidas; assim como examinar as diferentes linhas e referenciais teóricos utilizados como base para o entendimento do construto relacionado ao público-alvo; explorar os diferentes delineamentos e metodologias empregados; e, por fim, levantar os principais resultados obtidos.

\section{MÉTODO}

Realizou-se uma revisão integrativa da produção científica. Esse método possibilita sintetizar e analisar o que já se produziu, no que se refere à temáticaalvo, em estudos anteriores que adotaram as mais diversas metodologias (BOTELHO; CUNHA; MACEDO, 2011). Durante o planejamento desta revisão, adotou-se seis etapas: (I) identificação do tema e formulação da pergunta de pesquisa; (II) estabelecimento dos critérios de inclusão e exclusão; (III) identificação dos estudos pré-selecionados e selecionados; (IV) categorização dos estudos selecionados; (V) análise e interpretação dos resultados; e (VI) síntese do conhecimento (BOTELHO; CUNHA; MACEDO, 2011).

Elaborou-se a pergunta de pesquisa com base na estratégia $\mathrm{PVO}$, adaptação da técnica PICO. A sigla significa $(\mathrm{P})=$ população alvo, problema ou contexto; $(\mathrm{V})$ = definir a variável, quando houver; e $(\mathrm{O})$ outcomes/desfechos possíveis (BIRUEL; PINTO, 2011). A partir desta estratégia, formulou-se que: $(\mathrm{P})$ = produções científicas com sujeitos privados de liberdade; $(\mathrm{V})=$ abordagens sobre comportamento agressivo; e $(\mathrm{O})$ = identificar e descrever estudos encontrados. Por fim, extraiu-se a pergunta de pesquisa, formulada da seguinte forma: como a produção científica aborda o comportamento agressivo em sujeitos privados de liberdade?

Os critérios de inclusão da pesquisa consideraram estudos publicados entre 2010 e 2020, em português, inglês ou espanhol, que abordassem o comportamento agressivo em sujeitos imputáveis privados de liberdade. Por sua vez, os critérios de exclusão objetivaram, principalmente, selecionar estudos 
para a síntese qualitativa que correspondessem a uma única modalidade de encarceramento. Não entraram nesta revisão estudos com amostras compostas unicamente por crianças e/ou adolescentes privados de liberdade, já que o contexto de medidas socioeducativas aplicadas à menores infratores não é objeto de estudo desta revisão, assim como cenários em que a imputabilidade corresponda a faixas etárias menores que a brasileira. Também foram excluídas amostras com sujeitos privados de liberdade em hospitais de custódia/ psiquiátricos, com apenados que possuem somente sanções pecuniárias ou restritivas de direito e com indivíduos residentes em comunidades terapêuticas. Também foram excluídos, durante leitura de títulos e resumos, estudos que possuíssem modelos predominantemente biomédicos ou que direcionassem seu foco ao delito cometido.

A busca por produções científicas relacionadas ao tema ocorreu entre abril e maio de 2020. Optou-se pelas bases de dados Medical Literature Analysis and Retrieval System Online (MEDLINE), Literatura Latino-americana e do Caribe em Ciências da Saúde (LILACS), Índice Bibliográfico Espanhol de Ciências de Saúde (IBECS) - coleções do Índice Regional da Biblioteca Virtual em Saúde (BVS) - e Scientific Electronic Library Online (SciELO). Justifica-se a escolha das bases de dados pela relevância empírica apresentada nas produções dos diversos âmbitos da saúde. Os descritores controlados foram obtidos do Banco de Descritores em Ciências da Saúde (DeCS), sendo: prisões, prisioneiros, criminosos, crime e agressão. Com o intuito de também abarcar produções cientificas em inglês e espanhol, os mesmos descritores dos respectivos idiomas foram utilizados. Descritores não-controlados não foram utilizados. Nas buscas, aplicou-se um filtro temporal que considerava o período 2010 a 2020.

Os detalhes de pesquisa obtidos variaram de acordo com as características distintas entre os dois mecanismos de buscas. A sintaxe resultante da combinação de operadores booleanos é apresentada na Tabela 1. 
Tabela 1. Sintaxes utilizadas nos mecanismos de busca das bases de dados.

\begin{tabular}{|c|c|}
\hline Bases de dados & Sintaxe da busca \\
\hline $\begin{array}{c}\text { Portal BVS } \\
\text { (MEDLINE, } \\
\text { LILACS e IBECS) }\end{array}$ & $\begin{array}{l}\text { (tw:((tw:(prisoes)) OR (tw:(prisioneiros)) OR (tw:(criminosos)) } \\
\text { OR (tw:(crime)) OR (tw:(prisiones)) OR (tw:(prisioneros)) } \\
\text { OR (tw:(criminales)) OR (tw:(crimen)) OR (tw:(prisons)) OR } \\
\text { (tw:(prisoners)) OR (tw:(criminals)))) AND (tw:((tw:(agressao)) } \\
\text { OR (tw:(agresion)) OR (tw:(aggression)))) AND } \\
\text { db:("MEDLINE" OR “LILACS" OR "IBECS")) AND (year_ } \\
\text { cluster:[2010 TO 2020]) }\end{array}$ \\
\hline SciELO & $\begin{array}{l}\text { (prisoes OR prisioneiros OR criminosos OR crime OR prisiones } \\
\text { OR prisioneros OR criminales OR crimen OR prisons OR } \\
\text { prisoners OR criminals) AND (agressao OR agresion OR } \\
\text { aggression) AND year_cluster:("2010" OR "2011" OR "2012" } \\
\text { OR "2013" OR "2014" OR "2015" OR "2016" OR "2017" OR } \\
\text { "2018" OR "2019") }\end{array}$ \\
\hline
\end{tabular}

Nota: não houve resultados do ano de 2020 na base de dados SciELO. Fonte: autoria própria, 2020.

Todos os resultados encontrados em cada base de dados foram exportados no formato RIS e adicionados ao software EndNote X9, tornando-se possível identificar duplicatas (comparadas através de autoria, título e ano), organizar os resultados em grupos (pré-selecionados, selecionados e excluídos, subcategorizados de acordo com as bases de dados) e anexar a versão digital dos artigos nas referências, para então proceder a leitura na íntegra.

O processo de inclusão e exclusão de artigos é apresentado na Figura 1. 
Figura 1 - Fluxograma representativo da seleção de artigos de acordo com os Principais Itens para Análises Sistemáticas e Meta-análises (PRISMA Statement), (MOHER et al., 2009).

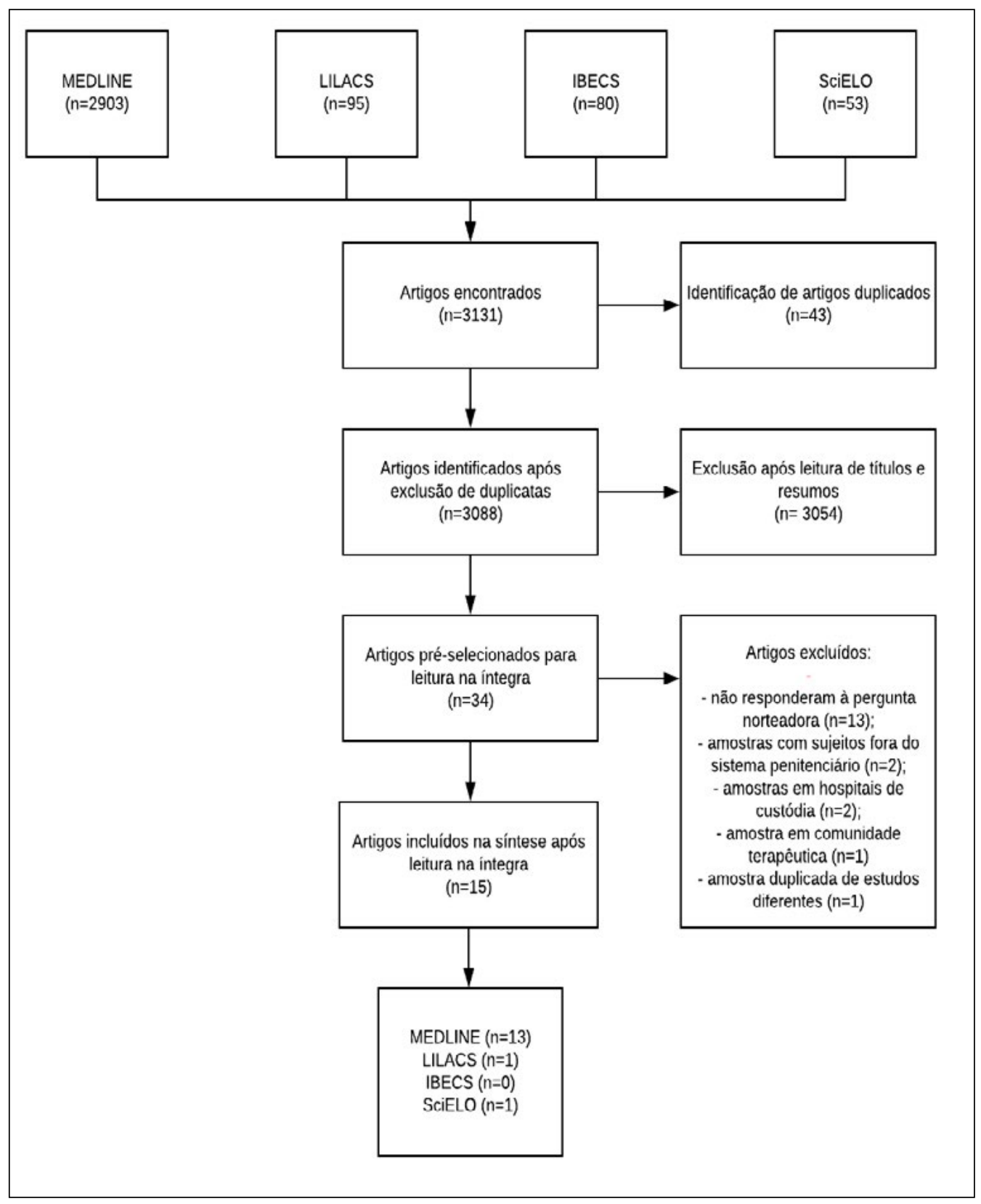

Fonte: autoria própria, 2020. 


\section{RESULTADOS}

A síntese qualitativa é composta por 15 artigos, encontrando-se a maioria $(87 \%)$ indexada pela base de dados MEDLINE. Das 80 produções inicialmente encontradas na base de dados IBECS, nenhuma entrou na síntese qualitativa, assim como estudos em espanhol. Todos os estudos, publicados entre $2011 \mathrm{e}$ 2019 , se concentraram em três continentes: americano, asiático e europeu. O país com maior número de artigos incluídos foi o Reino Unido, com três estudos. O periódico Aggressive Behavior, indexado pela base de dados MEDLINE, teve o maior número de artigos incluídos, sendo três ao todo (Tabela 2).

Tabela 2. Características dos estudos que abordaram a agressividade em sujeitos privados de liberdade.

\begin{tabular}{|c|c|c|c|c|}
\hline $\begin{array}{c}\text { Autor } \\
\text { País, ano }\end{array}$ & $\begin{array}{c}\text { Periódico } \\
\text { (Base de } \\
\text { dados) }\end{array}$ & $\begin{array}{l}\text { Objetivos relacionados } \\
\text { ao construto }\end{array}$ & $\begin{array}{l}\text { Delineamento e } \\
\text { amostra }\end{array}$ & Principais resultados \\
\hline $\begin{array}{l}\text { BAHRAMI, } \\
\text { Elaheh; } \\
\text { MAZAHERI, } \\
\text { Maryam Amidi; } \\
\text { HASANZADEH, } \\
\text { Akbar. } \\
\text { Irã, } 2016\end{array}$ & $\begin{array}{l}\text { Journal of } \\
\text { Education } \\
\text { and Health } \\
\text { Promotion } \\
\text { (MEDLINE) }\end{array}$ & $\begin{array}{l}\text { Investigar os efeitos } \\
\text { da intervenção em } \\
\text { gerenciamento da } \\
\text { raiva na saúde mental } \\
\text { e comportamento } \\
\text { agressivo de } \\
\text { prisioneiras. }\end{array}$ & $\begin{array}{l}\text { Estudo quase- } \\
\text { experimental (pré- } \\
\text { teste/pós-teste). } \\
\text { Amostra aleatória de } \\
168 \text { mulheres. }\end{array}$ & $\begin{array}{l}\text { A intervenção de } \\
\text { gerenciamento de raiva se } \\
\text { mostrou efetiva na redução } \\
\text { do comportamento agressivo. }\end{array}$ \\
\hline $\begin{array}{l}\text { BARKER, Lyndsie } \\
\text { Fiona, et al. } \\
\text { Reino Unido, } 2016\end{array}$ & $\begin{array}{l}\text { International } \\
\text { Journal of Law } \\
\text { and Psychiatry } \\
\text { (MEDLINE) }\end{array}$ & $\begin{array}{l}\text { Examinar a associação } \\
\text { entre qualidade e } \\
\text { quantidade do sono } \\
\text { autorreferida e como } \\
\text { estas se relacionam } \\
\text { com a motivação para a } \\
\text { agressão. }\end{array}$ & $\begin{array}{l}\text { Dois estudos } \\
\text { transversais com } \\
\text { duas amostras } \\
\text { distintas, sendo o } \\
\text { primeiro composto } \\
\text { por } 95 \text { presidiários } \\
\text { adultos. }\end{array}$ & $\begin{array}{l}\text { Aqueles que percebem má } \\
\text { qualidade do sono foram } \\
\text { mais propensos a relatar que } \\
\text { haviam cometido agressão } \\
\text { na semana anterior e a } \\
\text { apresentar níveis mais altos } \\
\text { de agressão implícita. }\end{array}$ \\
\hline $\begin{array}{l}\text { CARLI, Vladimir, } \\
\text { et al. } \\
\text { Itália, } 2014\end{array}$ & $\begin{array}{l}\text { Nord J } \\
\text { Psychiatry } \\
\text { (MEDLINE) }\end{array}$ & $\begin{array}{l}\text { - Determinar se a } \\
\text { agressividade-traço e a } \\
\text { impulsividade podem } \\
\text { estar associadas a } \\
\text { variáveis clínicas; } \\
\text { - detectar qualquer } \\
\text { associação desses } \\
\text { traços com medidas de } \\
\text { experiências traumáticas } \\
\text { precoces. }\end{array}$ & $\begin{array}{l}\text { Estudo transversal } \\
\text { realizado com uma } \\
\text { amostra de } 1356 \\
\text { presos. }\end{array}$ & $\begin{array}{l}\text { Sujeitos com histórico de } \\
\text { transtornos por uso de } \\
\text { substâncias, automutilação } \\
\text { e tentativa de suicídio } \\
\text { apresentaram escores mais } \\
\text { altos de agressividade. } \\
\text { Encontrou-se uma correlação } \\
\text { consistente entre os escores } \\
\text { da escala de agressão e as } \\
\text { experiências tramáticas } \\
\text { precoces. }\end{array}$ \\
\hline $\begin{array}{l}\text { DUNNE, Ashley } \\
\text { L., et al. } \\
\text { Austrália, } 2018\end{array}$ & $\begin{array}{l}\text { Aggressive } \\
\text { Behavior } \\
\text { (MEDLINE) }\end{array}$ & $\begin{array}{l}\text { Examinar associações } \\
\text { entre EPMAs, } \\
\text { modos de esquema } \\
\text { e comportamento } \\
\text { agressivo. }\end{array}$ & $\begin{array}{l}\text { Estudo observacional } \\
\text { e transversal } \\
\text { realizado em uma } \\
\text { amostra de } 208 \\
\text { infratores. }\end{array}$ & $\begin{array}{l}\text { Os EPMAs mostraram } \\
\text { associação significativa com a } \\
\text { agressividade e os modos de } \\
\text { esquema Criança Enfurecida, } \\
\text { Criança Impulsiva e } \\
\text { Provocativo e Ataque foram } \\
\text { significativamente preditores } \\
\text { de comportamento agressivo. }\end{array}$ \\
\hline $\begin{array}{l}\text { ESTEVES, } \\
\text { Germano Gabriel } \\
\text { Lima, et al. } \\
\text { Brasil, } 2018\end{array}$ & $\begin{array}{l}\text { Psico USF } \\
\text { (LILACS) }\end{array}$ & $\begin{array}{l}\text { Caracterizar fatores de } \\
\text { risco, especificamente, a } \\
\text { psicopatia, agressividade } \\
\text { e a personalidade, em } \\
\text { detentos brasileiros } \\
\text { inseridos em atividade } \\
\text { de ressocialização. }\end{array}$ & $\begin{array}{l}\text { Estudo transversal, } \\
\text { realizado em uma } \\
\text { amostra não- } \\
\text { probabilística e por } \\
\text { conveniência com } 48 \\
\text { detentos. }\end{array}$ & $\begin{array}{l}\text { O perfil se mostrou } \\
\text { divergente do tipicamente } \\
\text { reportado, indicando } \\
\text { baixa hostilidade, } \\
\text { psicopatia primária e uma } \\
\text { personalidade caracterizada } \\
\text { pela amabilidade e abertura a } \\
\text { mudança. }\end{array}$ \\
\hline
\end{tabular}




\begin{tabular}{|c|c|c|c|c|}
\hline $\begin{array}{c}\text { Autor } \\
\text { País, ano }\end{array}$ & $\begin{array}{l}\text { Periódico } \\
\text { (Base de } \\
\text { dados) }\end{array}$ & $\begin{array}{l}\text { Objetivos relacionados } \\
\text { ao construto }\end{array}$ & $\begin{array}{l}\text { Delineamento e } \\
\text { amostra }\end{array}$ & Principais resultados \\
\hline $\begin{array}{l}\text { FALK, Örjan, et al. } \\
\text { Suécia, } 2017\end{array}$ & $\begin{array}{l}\text { Psychiatry } \\
\text { Research } \\
\text { (MEDLINE) }\end{array}$ & $\begin{array}{l}\text { - Identificar a força } \\
\text { da associação entre } \\
\text { as dimensões da } \\
\text { personalidade e as } \\
\text { subclasses de traços de } \\
\text { agressividade entre todo } \\
\text { o grupo de infratores, } \\
\text { bem como por gênero } \\
\text { separadamente; } \\
\text { - estabelecer a } \\
\text { configuração de } \\
\text { personalidade mais forte } \\
\text { para explicar o traço de } \\
\text { agressividade. }\end{array}$ & $\begin{array}{l}\text { Estudo transversal } \\
\text { realizado com } \\
\text { infratores, sendo } \\
65 \text { homens e } 50 \\
\text { mulheres. }\end{array}$ & $\begin{array}{l}\text { - A maioria dos infratores } \\
\text { obteve uma pontuação alta } \\
\text { nos traços agressivos. Houve } \\
\text { associações que variaram de } \\
\text { moderadas a fortes entre as } \\
\text { dimensões da personalidade } \\
\text { e as subescalas que medem } \\
\text { o comportamento agressivo. } \\
\text { Essas associações foram } \\
\text { mais fortes na amostra de } \\
\text { agressoras. } \\
\text { - Estabeleceu-se o padrão de } \\
\text { temperamento impulsivo e } \\
\text { exploratório em combinação } \\
\text { com uma baixa maturidade } \\
\text { de caráter como o perfil } \\
\text { de personalidade mais } \\
\text { proeminente por trás de } \\
\text { comportamentos antissociais } \\
\text { agressivos. }\end{array}$ \\
\hline $\begin{array}{l}\text { FONTAO, Maria } \\
\text { Isabel; ROSS, } \\
\text { Thomas. } \\
\text { Alemanha, } 2018 .\end{array}$ & $\begin{array}{l}\text { Criminal } \\
\text { Behaviour and } \\
\text { Mental Health } \\
\text { (MEDLINE) }\end{array}$ & $\begin{array}{l}\text { Investigar agressividade, } \\
\text { lócus de controle e } \\
\text { estilo atribucional em } \\
\text { imigrantes presos na } \\
\text { Alemanha. }\end{array}$ & $\begin{array}{l}\text { Estudo transversal } \\
\text { realizado com três } \\
\text { grupos: } 67 \text { imigrantes } \\
\text { da antiga União } \\
\text { Soviética, sendo } \\
36 \text { presos e } 31 \text { sem } \\
\text { histórico de delitos, } \\
\text { além de } 40 \text { presos } \\
\text { nativos. }\end{array}$ & $\begin{array}{l}\text { A agressividade foi alta entre } \\
\text { todos os presos em relação } \\
\text { aos imigrantes não-infratores. } \\
\text { Em um modelo de regressão } \\
\text { com a agressividade como } \\
\text { variável dependente } \\
\text { e o lócus de controle } \\
\text { e medidas de estilo } \\
\text { atribucional como variáveis } \\
\text { independentes, apenas o } \\
\text { estilo atribucional externo } \\
\text { em relação ao fracasso } \\
\text { esteve significativamente } \\
\text { relacionado à agressividade. }\end{array}$ \\
\hline $\begin{array}{l}\text { GAROFALO, } \\
\text { Carlo, et al. } \\
\text { Itália, } 2016 .\end{array}$ & $\begin{array}{l}\text { Aggressive } \\
\text { Behavior } \\
\text { (MEDLINE) }\end{array}$ & $\begin{array}{l}\text { Ampliar o conhecimento } \\
\text { prévio sobre o vínculo } \\
\text { entre autoestima } \\
\text { e agressividade, } \\
\text { examinando o } \\
\text { papel mediador da } \\
\text { desregulação emocional } \\
\text { entre infratores e } \\
\text { participantes da } \\
\text { comunidade. }\end{array}$ & $\begin{array}{l}\text { Estudo transversal } \\
\text { realizado com duas } \\
\text { amostras: uma } \\
\text { composta por } 153 \\
\text { infratores violentos } \\
\text { e outra por } 197 \\
\text { indivíduos da } \\
\text { comunidade. }\end{array}$ & $\begin{array}{l}\text { Na amostra de infratores, os } \\
\text { modelos de mediação foram } \\
\text { significativos para três dos } \\
\text { quatro aspectos de traços de } \\
\text { agressividade considerados. } \\
\text { A desregulação da emoção } \\
\text { era mediada pelos vínculos } \\
\text { que a baixa autoestima tinha } \\
\text { com a agressão física, raiva e } \\
\text { hostilidade. }\end{array}$ \\
\hline $\begin{array}{l}\text { GONÇALVES, } \\
\text { Leonel Cunha; } \\
\text { GONÇALVES, } \\
\text { Rui Abrunhosa. } \\
\text { Portugal, } 2012 .\end{array}$ & $\begin{array}{l}\text { Psicologia USP } \\
\text { (SciELO) }\end{array}$ & $\begin{array}{l}\text { Identificar variáveis } \\
\text { sóciodemográficas } \\
\text { e jurídico-penais } \\
\text { relacionadas com a } \\
\text { agressividade e o estilo } \\
\text { de vida criminal. }\end{array}$ & $\begin{array}{l}\text { Estudo observacional } \\
\text { e de caráter } \\
\text { exploratório, } \\
\text { com amostra por } \\
\text { conveniência } \\
\text { realizada com } 31 \\
\text { reclusos portugueses. }\end{array}$ & $\begin{array}{l}\text { Verificou-se que o número } \\
\text { reduzido de visitas e idades } \\
\text { mais jovens são preditoras da } \\
\text { agressividade na prisão; } \\
\text { - a agressividade é uma das } \\
\text { variáveis que predizem uma } \\
\text { pior adaptação à prisão. }\end{array}$ \\
\hline $\begin{array}{l}\text { KALEMI, } \\
\text { Georgia, et al. } \\
\text { Grécia, } 2019 .\end{array}$ & $\begin{array}{l}\text { Women } \\
\text { \& Health } \\
\text { (MEDLINE) }\end{array}$ & $\begin{array}{l}\text { Explorar a relação } \\
\text { entre autoestima } \\
\text { e agressividade e } \\
\text { investigar possíveis } \\
\text { diferenças na autoestima } \\
\text { e agressividade entre } \\
\text { detentas e mulheres sem } \\
\text { antecedentes criminais. }\end{array}$ & $\begin{array}{l}\text { Estudo observacional } \\
\text { e transversal } \\
\text { composto por uma } \\
\text { amostra com } 307 \\
\text { mulheres, sendo } \\
157 \text { detentas e } \\
150 \text { mulheres } \\
\text { sem antecedentes } \\
\text { criminais. }\end{array}$ & $\begin{array}{l}\text { Menor autoestima } \\
\text { foi associada a maior } \\
\text { agressividade entre mulheres, } \\
\text { independentemente da } \\
\text { criminalidade. A autoestima } \\
\text { foi menor e a agressividade } \\
\text { maior nas reclusas do que } \\
\text { nas sem antecedentes. } \\
\text { No entanto, após o ajuste } \\
\text { por idade, escolaridade } \\
\text { e autoestima, a diferença } \\
\text { em relação à agressividade } \\
\text { deixou de ser estatisticamente } \\
\text { significante. }\end{array}$ \\
\hline
\end{tabular}




\begin{tabular}{|c|c|c|c|c|}
\hline $\begin{array}{l}\text { Autor } \\
\text { País, ano }\end{array}$ & $\begin{array}{l}\text { Periódico } \\
\text { (Base de } \\
\text { dados) }\end{array}$ & $\begin{array}{l}\text { Objetivos relacionados } \\
\text { ao construto }\end{array}$ & $\begin{array}{l}\text { Delineamento e } \\
\text { amostra }\end{array}$ & Principais resultados \\
\hline $\begin{array}{l}\text { LEHMANN, } \\
\text { Anja; } \\
\text { ITTEL, Angela. } \\
\text { Alemanha, } 2012 .\end{array}$ & $\begin{array}{l}\text { International } \\
\text { Journal of Law } \\
\text { and Psychiatry } \\
\text { (MEDLINE) }\end{array}$ & $\begin{array}{l}\text { Obter dados sobre } \\
\text { a prevalência de } \\
\text { psicopatia entre } \\
\text { mulheres presas e } \\
\text { examinar possíveis } \\
\text { relações entre os tipos } \\
\text { e motivos de agressão, } \\
\text { comportamento pró- } \\
\text { social e escores na Escala } \\
\text { Hare PCL-R. }\end{array}$ & $\begin{array}{l}\text { Estudo observacional } \\
\text { e transversal } \\
\text { realizado em uma } \\
\text { amostra com } 60 \\
\text { mulheres presas. }\end{array}$ & $\begin{array}{l}\text { Obteve-se uma taxa de } \\
\text { prevalência de psicopatia } \\
\text { de } 17 \%(\mathrm{~N}=10 \text {, com um } \\
\text { ponto de corte de } 25) \text {. } \\
\text { Considerando-se uma } \\
\text { ampla gama de subtipos de } \\
\text { comportamentos agressivos, } \\
\text { descobriu-se que a agressão } \\
\text { física proativa e reativa } \\
\text { relacional, bem como a idade, } \\
\text { foram preditores de altos } \\
\text { escores de psicopatia. }\end{array}$ \\
\hline $\begin{array}{l}\text { OHLSSON, Ioan } \\
\text { M.; } \\
\text { IRELAND, Jane L. } \\
\text { Reino Unido, } \\
2011 .\end{array}$ & $\begin{array}{l}\text { Aggressive } \\
\text { Behavior } \\
\text { (MEDLINE) }\end{array}$ & $\begin{array}{l}\text { Examinar a motivação } \\
\text { do comportamento } \\
\text { agressivo, ampliando-a } \\
\text { para incluir a motivação } \\
\text { da ofensa. }\end{array}$ & $\begin{array}{l}\text { Estudo observacional } \\
\text { e transversal em uma } \\
\text { amostra com } 206 \\
\text { homens presos. }\end{array}$ & $\begin{array}{l}\text { A motivação da agressão } \\
\text { se separou em quatro } \\
\text { motivos principais: proteção, } \\
\text { reconhecimento social, } \\
\text { resultado positivo percebido } \\
\text { e prazer. Verificou-se que } \\
\text { infratores violentos e não } \\
\text { violentos diferem em seus } \\
\text { motivos subjacentes a atos } \\
\text { recentes de agressão. }\end{array}$ \\
\hline $\begin{array}{l}\text { RIVERA, Echo A.; } \\
\text { KUBIAK, Sheryl } \\
\text { P.; } \\
\text { BYBBE, Deborah. } \\
\text { Estados Unidos, } \\
2014 .\end{array}$ & $\begin{array}{l}\text { Am J } \\
\text { Community } \\
\text { Psychol } \\
\text { (MEDLINE) }\end{array}$ & $\begin{array}{l}\text { Investigar as múltiplas } \\
\text { experiências de } \\
\text { violência (perpetração } \\
\text { e vitimização), como } \\
\text { a agressão, contra } \\
\text { parceiros e terceiros. }\end{array}$ & $\begin{array}{l}\text { Estudo de } \\
\text { levantamento } \\
\text { em uma amostra } \\
\text { aleatória com } \\
580 \text { mulheres } \\
\text { encarceradas. }\end{array}$ & $\begin{array}{l}\text { O histórico de vitimização } \\
\text { estava relacionado a um } \\
\text { aumento do risco de } \\
\text { agressões e variava de } \\
\text { acordo com o alvo e o tipo de } \\
\text { agressão perpetrada. }\end{array}$ \\
\hline $\begin{array}{l}\text { SHOREY, Ryan } \\
\text { C., et al. } \\
\text { Estados Unidos, } \\
2011 .\end{array}$ & $\begin{array}{l}\text { Journal of } \\
\text { Interpersonal } \\
\text { Violence } \\
\text { (MEDLINE) }\end{array}$ & $\begin{array}{l}\text { Examinar a associação } \\
\text { entre traço de raiva, } \\
\text { impulsividade, } \\
\text { perpetração de violência } \\
\text { por parceiro íntimo e } \\
\text { agressão geral entre } \\
\text { mulheres presas por } \\
\text { violência doméstica. }\end{array}$ & $\begin{array}{l}\text { Estudo transversal } \\
\text { com } 80 \text { mulheres } \\
\text { presas por violência } \\
\text { doméstica. }\end{array}$ & $\begin{array}{l}\text { Os resultados indicaram que } \\
\text { tanto o traço de raiva quanto } \\
\text { a impulsividade estavam } \\
\text { significativamente associados } \\
\text { à perpetração de agressão e } \\
\text { o traço de raiva mediava a } \\
\text { relação entre impulsividade e } \\
\text { perpetração de agressão. }\end{array}$ \\
\hline $\begin{array}{l}\text { TEW, J. et al. } \\
\text { Reino Unido, } \\
2012 .\end{array}$ & $\begin{array}{l}\text { Criminal } \\
\text { Behaviour and } \\
\text { Mental Health } \\
\text { (MEDLINE) }\end{array}$ & $\begin{array}{l}\text { Relatar informações } \\
\text { relacionadas a mudanças } \\
\text { relacionadas à raiva e } \\
\text { agressão em usuários } \\
\text { de um programa de } \\
\text { redução de violência. }\end{array}$ & $\begin{array}{l}\text { Estudos de caso } \\
\text { único com cinco } \\
\text { sujeitos em uma } \\
\text { penitenciária de } \\
\text { segurança máxima. }\end{array}$ & $\begin{array}{l}\text { As descobertas sugerem } \\
\text { que, ainda na prisão, os } \\
\text { sujeitos experimentaram } \\
\text { uma redução na raiva } \\
\text { autorreferida. Após } \\
\text { deixarem a penitenciária } \\
\text { (por progressão de pena } \\
\text { ou mudança de presídio), } \\
\text { registrou-se menores } \\
\text { incidentes de agressão física, } \\
\text { mas houve níveis mais } \\
\text { altos do que o esperado de } \\
\text { agressão verbal. }\end{array}$ \\
\hline
\end{tabular}

Nota: EPMAs = Esquemas Precoces Mal Adaptativos. Fonte: autoria própria, 2020.

\section{DISCUSSÃO}

Grande parte dos estudos sintetizados buscaram relacionar o comportamento agressivo com outras variáveis, como a psicopatia, a raiva e a personalidade.

A psicopatia, também referida como transtorno da personalidade antissocial, é definida pelo Manual Diagnóstico e Estatístico de Transtornos Mentais (DSM-5) como "um padrão difuso de indiferença e violação dos 
direitos dos outros" (Associação Americana de Psicologia, APA, 2014, p. 659), tendo como critérios diagnósticos o fracasso em se ajustar às normas sociais, a tendência à falsidade, a impulsividade, a agressividade, o descaso pela segurança de si e dos outros, a irresponsabilidade reiterada e a ausência de remorso (Associação Americana de Psicologia, APA, 2014). No estudo de Esteves et al. (2018), escores de psicopatia e agressividade foram inferiores aos de amostras compostas por universitários, o que não poderia ser explicado pela relação - ausente - entre os escores observados e as atividades de ressocialização nas quais os sujeitos estavam inseridos, levando os autores a considerarem a possibilidade de que a utilização de instrumentos autoaplicados podem ter influência na aferição de traços de psicopatia, podendo os indivíduos com tais características manipular suas respostas para apresentar escores inferiores. A relação entre psicopatia e o comportamento agressivo também foi objetivo do estudo de Lehmann e Ittel (2012), realizado em uma amostra com mulheres presas, onde subtipos de agressividade foram preditores de altos escores de psicopatia.

Sujeitos com traços de psicopatia inseridos em um programa de redução de violência em penitenciárias de segurança máxima experimentaram redução na raiva (Tew et al., 2012), construto este que, associado com a agressividade, teve relevância em outros três estudos, nos quais se constataram o seu papel mediador na perpetração da agressão e desregulação da emoção e a importância de se desenvolver programas em gerenciamento de raiva (BAHRAMI; MAZAHERI; HASANZADEH, 2016; LEHMANN; ITTEL, 2012; TEW et al., 2012).

Abordou-se a personalidade, relacionada com o comportamento agressivo, através de diferentes perspectivas teóricas e instrumentos. Uma personalidade caracterizada pela amabilidade e abertura a mudança, mensurada pelo Inventário dos Cinco Grandes Fatores da Personalidade, foi identificada no levantamento de Esteves et al. (2018), e a divergência destes resultados com outros anteriormente reportados são indicativos, na visão dos autores, de respostas motivadas por desejabilidade social. Falk et al. (2017), por sua vez, identificaram um padrão de temperamento impulsivo e exploratório por trás de comportamentos antissociais agressivos, ao avaliarem a personalidade através do Inventário de Temperamento e Caráter de Cloninger.

A impulsividade é um outro construto frequentemente abordado, mas que igualmente deve ser diferenciado, já que resulta em diferentes impactos quando em conjunto com outras variáveis, ao mesmo tempo em que possui associação significativa com a agressividade (CARLI et al., 2014; SHOREY et al., 2011).

Comparações sociodemográficas também se fizeram presentes na literatura. Falk et al. (2017) utilizaram-se de uma amostra composta por homens e mulheres, ambos detentos, e sustentaram suas hipóteses nos registros que indicavam uma predisposição congênita à criminalidade afetando mais as 
mulheres. Fontao e Ross (2018) compararam imigrantes vindos da ex-União Soviética sem histórico de crimes, imigrantes de mesma origem presos, além de presos nascidos na Alemanha, país onde a pesquisa ocorreu, e corroboraram a hipótese de pesquisa que apontava agressividade alta entre todos os presos em relação aos imigrantes não-infratores. Garofalo et al. (2017) compararam sujeitos privados de liberdade violentos e indivíduos da comunidade, e os achados desta pesquisa sugerem que a desregulação da emoção desenvolve um importante papel na conexão entre baixa autoestima e agressão física entre infratores, bem como entre indivíduos da comunidade, acrescentandose a agressão verbal presente nestes últimos. A relação entre baixa autoestima e agressividade também é encontrada em estudos que envolvem mulheres com ou sem antecedentes criminais (KALEMI, 2019). Amostras com mulheres compuseram seis estudos ao todo, número significativo dada a subrepresentação deste grupo em prisões (ICPR, 2020).

Barker et al. (2016) conduziram dois estudos independentes, sendo o primeiro composto por uma amostra de 95 detentos adultos e o segundo por jovens adultos detidos com média de idade de 19.5 anos. Com base nos critérios de exclusão, somente o primeiro foi considerado nesta síntese, estudo este que objetivou relacionar quantidade e qualidade de sono com o comportamento agressivo, obtendo como resultado o indicador de que má qualidade de sono autorreferida se associou com este comportamento.

O método identificado pouco variou, considerando-se que a maioria se utilizou de levantamentos transversais descritivo-correlacionais ou explicativos. Destacam-se, portanto, dois trabalhos: Tew et al. (2012) realizaram múltiplos estudos de caso único - cinco ao todo - em um programa de redução da violência em unidades prisionais de segurança máxima; Bahrami, Mazaheri e Hasanzadeh (2016), por sua vez, adotaram um delineamento quaseexperimental, no qual as detentas responderam ao Questionário de Agressão de Buss-Perry, e as selecionadas com base nos maiores escores da escala participaram de uma intervenção em gerenciamento de raiva composta por quatro sessões que consistiam em leituras, questões e discussões em grupo e, um mês após a última sessão, foram novamente avaliadas através do Questionário de Agressão de Buss-Perry. Entre todos os artigos, o Questionário de Agressão de Buss-Perry, validado mundialmente e adaptado para o contexto brasileiro por Gouveia et al. (2008), foi o mais utilizado (cinco estudos).

Fatores contextuais também foram abordados. Gonçalves e Gonçalves (2012) apontaram o consumo de drogas, agressividade e idades mais jovens como os preditores mais significativos das infrações na prisão, corroborando o estudo de Lahm (2007). Rivera, Kubiak e Bybee (2014), ao investigarem as múltiplas experiências de violência, constataram que o histórico de vitimização estava relacionado a um aumento do risco de agressões, resultado que em partes dialoga com o estudo de Cima, Smeets e Jelicic (2008), acerca de experiências traumáticas precoces, enquanto que Ohlsson e Ireland (2011), 
examinando a motivação do comportamento agressivo, indicaram que a proteção, o reconhecimento social, o resultado positivo percebido e o prazer foram as principais motivações.

A investigação de Ohlsson e Ireland (2011) discutiu, ainda, implicações teóricas acerca dos resultados relacionados às principais motivações: a predição de que haveria uma dicotomia entre comportamento agressivo proativo e reativo não foi suportada pelos achados, e apontaram que este comportamento em sujeitos privados de liberdade pode ser melhor compreendido através de múltiplas motivações.

Dentre as concepções acerca do comportamento agressivo, a que diferencia a agressão reativa da proativa sustentou o referencial teórico de alguns trabalhos (BARKER et al., 2016; CARLI et al., 2014; LEHMANN; ITTEL, 2012; OHLSSON; IRELAND, 2011). Da mesma forma, a concepção de Bushman e Anderson (2001) também se fez presente, sendo frequentemente usada para definir brevemente o conceito de agressão ou agressividade e seus componentes cognitivos e emocionais (BARKER et al., 2011; DUNNE et al., 2018; ESTEVES et al, 2018; GAROFALO et al., 2016; KAMELI et al., 2019).

Alguns autores optaram por conduzir suas pesquisas à luz de teorias que iam além do da fundamentação teórica que explorava somente o comportamento agressivo. A saber, Dunne et al. (2018) examinaram as relações entre Esquemas Precoces Mal Adaptativos (EPMAs), conceito da Terapia do Esquema, com a agressão. Os EPMAs podem ser definidos como padrões disfuncionais de crenças relacionadas a percepção de si e do ambiente, esquemas estes estabelecidos ainda na infância, que por terem sido eficazes em algumas situações, são interpretados como eficazes em diversas outras, acompanhando a vida adulta (YOUNG et al., 2003).

A proposta de compreender o comportamento agressivo em conjunto com o estilo atribucional, conceito este proveniente da Psicologia Social e desenvolvido, dentre outros teóricos, por Rotter (1966) e Weiner (1986), partiu do estudo de Fontao et al., (2018), no qual os autores investigaram o lócus de controle, o estilo atribucional e a agressão entre imigrantes presos.

Por fim, a Teoria do Comportamento Planejado (TCP) é apresentada no estudo de Ohlsson e Ireland (2011), que investigou as motivações do comportamento agressivo. Esta teoria afirma que as intenções e comportamentos de um indivíduo são moldadas por três variáveis: controle comportamental percebido, a intenção em relação à atitude e as normas subjetivas (AJZEN, 1991).

Em resumo, a presente revisão integrativa investigou as diferentes abordagens acerca do comportamento agressivo de acordo com a produção acadêmica da última década. Esta escolha temporal, que abrange o período de 2010 a 2020, pode ser considerada uma limitação, já que contemplou dados de um intervalo de pouco mais de dez anos, podendo estes se encontrarem defasados. 
A busca em somente três bases de dados e por estudos unicamente em três idiomas também deve ser considerada uma limitação, já que impossibilitou a obtenção de resultados mais abrangentes, considerando-se a possibilidade de existirem artigos com qualidade metodológica abarcados por estes filtros.

Ressalta-se a importância desta revisão, enquanto primeira a integrar, em âmbito nacional e internacional, os múltiplos trabalhos que se propuseram a abordar o comportamento agressivo em sujeitos privados de liberdade, conhecimento este fundamental na ponderação de políticas públicas que promovam a redução da violência através de programas de adaptação dos reclusos ao contexto prisional e estratégias que busquem sua reinserção na sociedade.

\section{CONSIDERAÇÕES FINAIS}

A produção científica que abordou o comportamento agressivo em sujeitos privados de liberdade, metodologicamente, restringe-se a estudos de levantamento transversais descritivo-correlacionais ou explicativos, evidenciando a lacuna existente no que diz respeito a outros delineamentos possíveis. A definição de comportamento agressivo pode compreender múltiplas motivações, bem como se restringir a dicotomia entre agressão proativa ou reativa, instrumental ou impulsiva. O referencial teórico abarca teorias que compreendem os componentes cognitivos, emocionais e contextuais da agressividade.

O uso de escalas, questionários e inventários é o método mais empregado na abordagem do construto estudado, mas este é por sua vez compreendido em conjunto com outras variáveis, estas que muitas vezes possuem associação significativa, além de poderem ser preditoras do comportamento agressivo.

Sugere-se que os esforços em compreender a dinâmica biopsicossocial destes indivíduos alcancem, além da agressividade, construtos como a raiva, impulsividade e psicopatia, bem como fatores contextuais e sociodemográficos, valendo-se de metodologias já estabelecidas e de novos desenhos, e também da pluralidade de referenciais teóricos.

\section{REFERÊNCIAS ${ }^{2}$}

ASSOCIAÇÃO AMERICANA DE PSICOLOGIA [APA]. Manual diagnóstico e estatístico de transtornos mentais DSM-V-TR. Porto Alegre: ArtMed, 2014.

BAHRAMI, Elaheh; MAZAHERI, Maryam Amidi; HASANZADEH, Akbar. Effect of anger management education on mental health and aggression of prisoner women.

2 De acordo com a Associação Brasileira de Normas Técnicas (ABNT NBR 6023). 
Journal of Education and Health Promotion, v. 5, p. 1-5, 2016. DOI: http:/ /dx.doi. org/10.4103/2277-9531.184563.

BARKER, Lyndsie Fiona; IRELAND, Jane L.; CHU, Simon; IRELAND, Carol A. Sleep and its association with aggression among prisoners: Quantity or quality? International Journal of Law and Psychiatry, v. 47, p. 115-121, 2016. DOI: http:/ / dx.doi.org/10.1016/j.ijlp.2016.02.014.

BERKOWITZ, Leonard. Affective aggression: the role of stress, pain, and negative affect. In GEEN, R. G.; DONNERSTEIN, E. (orgs.). Human aggression: Theories, research, and implications for social policy. California: Academic Press, 1998. p. 49-72.

BOTELHO, Louise Lira Roedel; CUNHA, Cristiano Castro de Almeida; MACEDO, Marcelo. O método da revisão integrativa nos estudos organizacionais. Gestão e Sociedade, v. 5, n. 11, p. 121-136, maio/ago. 2011. DOI: https://doi.org/10.21171/ges. v5i11.1220.

BIRUEL, Elisabeth Peres; PINTO, Rosemeire Rocha. Bibliotecário: um profissional a serviço da pesquisa. In: Congresso Brasileiro de Biblioteconomia,Documentação e Ciência da Informação, 24., 2011, Maceió. Anais [...]. Maceió: Universidade Federal de Alagoas, 2011.

BOTTI, Nadja Cristiane Lappann; MACHADO, Jacqueline Simone de Almeida. Comportamento violento entre usuários de crack. Avances en Enfermería, Bogotá, v. 33, n. 1, p. 75-84, enero/abr. 2015. DOI: http://dx.doi.org/10.15446/av.enferm. v33n1.37379.

BOURAS, N. Social challenges of contemporary psychiatry. Psychiatriki, v. 28, n. 3, p. 119-202, 2017. DOI: http://dx.doi.org/10.22365/jpsych.2017.283.199.

BUSHMAN, Brad. J; ANDERSON, Craig. A. Is it time to pull the plug on hostile versus instrumental aggression dichotomy? Psychological Review, v. 108, n. 1, p. 273-279, 2001. DOI: http:/ /dx.doi.org/10.1037/0033-295x.108.1.273.

CIMA, Maaike; RAINE, Adrian. Distinct characteristics of psychopathy relate to different subtypes of aggression. Personality and Individual Differences, v. 47, n. 8, p. 835-840, 2009. DOI: http://dx.doi.org/10.1016/j.paid.2009.06.031.

CIMA, Maaike; SMEETS, Tom; JELICIC, Marko. Self-reported trauma, cortisol levels, and aggression in psychopathic and non-psychopathic prison inmates. Biological Psychology, v. 78, n. 1, p. 75-86, 2008. DOI: http://dx.doi.org/10.1016/j. biopsycho.2007.12.011.

COMAI, Stefano; BERTAZZO, Antonella; VACHON, Jeanne; DAIGLE, Marc; TOUPIN, Jean; CÔTÉ, Gilles; GOBBI, Gabriella. Trace elements among a sample of prisoners with mental and personality disorders and aggression: correlation with impulsivity and ADHD indices. Journal of Trace Elements in Medicine and Biology, v. 51, p. 123-129, 2019. DOI: https://doi.org/10.1016/j.jtemb.2018.10.008. 
CRICK, N. R.; DODGE, K. A. A Review and Reformulation of Social InformationProcessing Mechanisms in Children's Social Adjustment. Psychological Bulletin, v. 115, n. 1, p. 74-101, 1994. DOI: https:/ / doi.org/10.1037/0033-2909.115.1.74.

CUOMO, Chiara; SARCHIAPONE, Marco; DI GIANNANTONIO, Massimo; MANCINI, Michele; ROY, Alec. Aggression, Impulsivity, Personality Traits, and Childhood Trauma of Prisoners with Substance Abuse and Addiction. The American Journal of Drug and Alcohol Abuse, v. 34, n. 3, p. 339-345, 2008. DOI: http:/ /dx.doi. org/10.1080/00952990802010884.

DUNNE, Ashley L.; GILBERT, Flora; LEE, Stuart; DAFFERN, Michael. The role of aggression-related early maladaptive schemas and schema modes in aggression in a prisoner sample. Aggressive Behavior, v. 44, n. 3, p. 246-256, 2018. DOI: http:/ / dx.doi.org/10.1002/ab.21747.

ESTEVES, Germano Gabriel Lima; COELHO, Jorge Artur Peçanha de Miranda; BARROS, Bruna Nogueira Romariz; SOUZA, Gustavo Henrique Silva de. Caracterização de fatores de risco para o comportamento criminal em detentos. Psico USF, v. 23, n. 4, p. 719-730, 2018. DOI: http:/ /dx.doi.org/10.1590/141382712018230411.

FALK, Örjan; SFENDLA, Anis; BRÄNDSTRÖM, Sven; ANCKARSÄTER, Henrik; NILSSON, Thomas; KEREKES, Nóra. Personality and trait aggression profiles of male and female prison inmates. Psychiatry Research, v. 250, p. 302-309, Apr. 2017. DOI: http:/ /dx.doi.org/10.1016/j.psychres.2016.12.018.

FAVRIL, Louis; INDIG, Devon; GEAR, Craig; WILHELM, Key. Mental disorders and risk of suicide attempt in prisoners. Social Psychiatry and Psychiatric Epidemiology, 2020. DOI: https:/ /doi.org/10.1007/s00127-020-01851-7.

FONTAO, Maria Isabel; ROSS, Thomas. Aggression, attributional style, and locus of control among imprisoned migrants from the former Soviet Union. Criminal Behaviour and Mental Health, v. 28, n. 6, p. 466-475, Sept. 2018. DOI: http:/ /dx.doi. org/10.1002/cbm.2087.

GAROFALO, Carlo; HOLDEN, Christopher J.; ZEIGLER-HILL, Virgil; VELOTTI, Patrizia. Understanding the connection between self-esteem and aggression: The mediating role of emotion dysregulation. Aggressive Behavior, v. 42, n. 1, p. 3-15, 2016. DOI: http:/ /dx.doi.org/10.1002/ab.21601.

GONÇALVES, Leonel Cunha; GONÇALVES, Rui Abrunhosa. Agressividade, estilo de vida criminal e adaptação à prisão. Psicologia USP, São Paulo, v. 23, n. 3, p. 559-584, out. 2012. DOI: https://doi.org/10.1590/S0103-65642012005000013.

GOUVEIA, Valdiney V.; CHAVES, Célia Maria Cruz Marques; PEREGRINO, Rejane Ramos. Medindo a agressão: o Questionário de Buss-Perry. Arquivos Brasileiros de Psicologia, Rio de Janeiro, v. 60, n. 3, p. 92-103, 2008. Disponível em: https:/ /www. researchgate.net/publication/279194679_Measuring_aggression_The_Buss-Perry_ Questionnaire. Acesso em: 4 maio 2020. 
INFOPEN. Levantamento Nacional de Informações Penitenciárias Dezembro de 2019: painel interativo dezembro/2019. Brasília: DEPEN, 2019. Disponível em: http:/ / depen.gov.br/DEPEN/depen/sisdepen/infopen. Acesso em: 10 abr. 2020.

INSTITUTE FOR CRIMINAL POLICY RESEARCH (ICPR). World Prison Brief. World Prison Population List, 2020. Disponível em: https:/ / www.prisonstudies.org/ highest-to-lowest/prison-population-total. Acesso em: 10 abr. 2020.

KALEMI, Georgia; MICHOPOULOS, Ioannis; EFSTATHIOU, Vasiliki; TZEFERAKOS, Georgios; GKIOKA, Sevasti; GOURNELLIS, Rossetos; DOUZENIS, Athanassios. Self-esteem and aggression in women: differences between female prisoners and women without criminal records. Women Health, v. 59, n. 10, p. 1199-1211, 2019. DOI: https:/ / doi.org/10.1080/03630242.2019.1593284.

KRISTENSEN, Christian Haag; LIMA, Juliane Silveira; FERLIN, Mirela; FLORES, Renato Zamora; HACKMANN, Patrícia Hauschild. Fatores etiológicos da agressão física: uma revisão teórica. Estudos de Psicologia (Natal), v. 8, n. 1, p. 175-184, jan./ abr. 2003. DOI: https://doi.org/10.1590/S1413-294X2003000100020.

LAHM, Karen. F. Inmate-On-Inmate Assault: A Multilevel Examination of Prison Violence. Criminal Justice and Behavior, v. 35, n. 1, 120-137, 2007. DOI: http:/ / dx.doi.org/10.1177/0093854807308730.

LEHMANN, Anja; ITTEL, Angela. Aggressive behavior and measurement of psychopathy in female inmates of German prisons--a preliminary study. International Journal of Law and Psychiatry, v. 35, n. 3, p. 190-197, 2012. DOI: http:/ /dx.doi. org/10.1016/j.ijlp.2012.02.007.

MCGUIRE, James. A review of effective interventions for reducing aggression and violence. Philosophical Transactions of the Royal Society B: Biological Sciences, v. 363, n. 1503, p. 2577-2597, 2008. DOI: http:/ / doi.dx.org/10.1098/rstb.2008.0035.

MOHER, David.; LIBERATI, Alessandro.; TETZLAFF, Jennifer.; ALTMAN, Douglas. G.; The PRISMA Group. (2009). Preferred reporting items for sistematic reviews and meta-analyses: The PRISMA Statement. Plos med, v. 6, n. 7, e1000097, p. 1-7, 2009. DOI: http:/ / doi.dx.org/10.1371/journal.pmed.1000097.

OHLSSON, Ioan M.; IRELAND, Jane L. Aggression and offence motivation in prisoners: exploring the components of motivation in an adult male sample. Aggressive Behavior, v. 37, n. 3, p. 278-288, Mar. 2011. DOI: http:/ /dx.doi. org/10.1002/ab.20386.

RIVERA, Echo A.; KUBIAK, Sheryl P.; BYBEE, Deborah. Patterns of Women's Aggression Against Partners and Others: Broadening Our Understanding of Violence. Am J Community Psychol, v. 54, n. 3-4, p. 358-369, 2014. DOI: http://dx.doi. org/10.1007/s10464-014-9679-6. 
ROTTER, Julian. B. Generalized expectancies for internal versus external control of reinforcement. Psychological Monographs, v. 80, n. 1, p. 1-28, 1966. DOI: https:/ /doi. org/10.1037/h0092976.

SHELTON, Deborah; BARTA, Bill; TRESTMAN, Robert; WAKAI, Sara. Biopsychosocial Vulnerability-Stress Modeling for an Incarcerated Population. Journal for Evidence-based Practice in Correctional Health, v. 1, n. 1, p. 1-89, Aug. 2016. Disponível em: https:/ /opencommons. uconn.edu/cgi/viewcontent.cgi?referer=https:/ / scholar.google.com. br / \&httpsredir=1\&article=1002\&context=jepch. Acesso em: 10 abr. 2020.

SHOREY, Ryan C.; BRASFIELD, Hope; FEBRES, Jeniimarie; STUART, Gregory L. The association between impulsivity, trait anger, and the perpetration of intimate partner and general violence among women arrested for domestic violence. Journal of Interpersonal Violence, v. 26, n. 13, p. 2681-2697, 2011. DOI: http:/ / dx.doi. org/10.1177/0886260510388289.

TAVARES, Gislaine Pereira; SCHEFFER, Morgana; ALMEIDA, Rosa Maria Martins de. Drogas, violência e aspectos emocionais em apenados. Psicologia: Reflexão e Crítica, Porto Alegre, v. 25, n. 1, p. 89-95, 2012. Disponível em: http:/ /www.scielo.br/ scielo.php?script=sci_arttext\&pid=S0102-79722012000100011. Acesso em: 11 abr. de 2020 .

TEDESCHI, James T.; FELSON, Richard B. Violence, Aggression, and Coercive Actions. Washington DC: American Psychological Association, 1994.

TEW, J.; DIXON, L.; HARKINS, L.; BENNETT, A. Investigating changes in anger and aggression in offenders with high levels of psychopathic traits attending the Chromis violence reduction programme. Criminal Behaviour and Mental Health, v. 22, n. 3, p. 191-201, 2012. DOI: http:/ / dx.doi.org/10.1002/cbm.1832.

WEINER, Bernard. An attributional theory of motivation and emotion. New York: Springer, 1986. 